\title{
O Professor-Narrador: Autoridade e responsabilidade como estratégia docente
}

\author{
Sidmar Silveira Gomes \\ Universidade Estadual de Maringá - EUM, Maringá/PR, Brasil \\ Email: sidmar.gomes@uol.com.br
}

\section{Resumo}

Ao partir da problematização de dizeres naturalizados no que tange à função-docente, articulados a atuais discussões sobre a Base Nacional Comum Curricular (BNCC), a presente reflexão intenta ensaiar a função professor de teatro pela perspectiva de um professor-narrador: figura que ao narrar o mundo integraria a ele as gerações vindouras. Participa desta discussão os temas da tradição, da autoridade e da responsabilidade no campo educacional, debatidos por Hannah Arendt, a função do narrador, rememorada por Walter Benjamin, assim como as ideias de governo e de atitude crítica, legadas pelo pensador francês Michel Foucault. A armação argumentativa da reflexão, desafiando-se a uma abordagem outra do professor de teatro, dialoga com referências exógenas às práticas teatrais e educacionais: o filme Teorema (1986), do italiano Pier Paolo Pasolini, e a obra literária Fahrenheit 451, do norte-americano Ray Bradbury.

Palavras-chave

Função-Docente. Professor-Narrador. BNCC.

Pedagogia do Teatro.
Starting from the problematization of naturalized sayings with respect to the teaching function, articulated to current discussions on the National Common Curricular Base (BNCC), the present reflection intends to rehearse the role of theater teacher from the perspective of a teacher-narrator: a figure that narrating the world would integrate future generations to it. Participating in this discussion are the themes of tradition, authority and responsibility in the educational field, discussed by Hannah Arendt, the role of the narrator, recalled by Walter Benjamin, as well as the ideas of government and critical attitude, bequeathed by the French thinker Michel Foucault. The argumentative framework of reflection, challenging a different approach from the theater teacher, dialogues with exogenous references to theatrical and educational practices: the film Theorem, by the Italian Pier Paolo Pasolini, and the literary work Fahrenheit 451, by the American Ray Bradbury.

Keywords

Teaching Function. Teacher-Narrator. BNCC. Theater Pedagogy. 


\section{Sobre uma certa ideia da função-professor de teatro}

A Base Nacional Comum Curricular (BNCC), documento de caráter normativo, é responsável por definir "o conjunto orgânico e progressivo de aprendizagens essenciais que todos os alunos devem desenvolver ao longo das etapas e modalidades da Educação Básica, de modo a que tenham assegurados seus direitos de aprendizagem e desenvolvimento" (BRASIL, 2017, p. 7). A implementação dessa base suscitou acaloradas discussões em diversos campos da Educação, ainda hoje não arrefecidas.

Entre os seus defensores estão aqueles que advogam a favor do estabelecimento de uma base norteadora da educação como promessa para a diminuição de diferenças, sobretudo qualitativas, características de um país de extensão territorial continental e, também por isso, detentor de realidades socioeconômicas e políticas profundamente díspares. Portanto, como forma de garantia da equidade e da igualdade no que tange às condições de acesso à educação.

Do outro lado estão os que veem o documento como uma resposta favorável a interesses neoliberais, tributários de uma formação instrumental, focada no mercado de trabalho, ávido por profissionais tecnicamente bem formados, eficientes e competitivos. Esses últimos complementam seus argumentos atentando para os riscos inerentes a uma padronização do ensino, a qual comprometeria o poder de autonomia dos projetos político-pedagógicos desejados por cada comunidade escolar.

Em linhas gerais, a BNCC privilegia o desenvolvimento de habilidades e competências, as quais tangenciam diferentes campos do conhecimento, em detrimento à ênfase na transmissão de conteúdos específicos. Ao enfatizar o desenvolvimento de habilidades e de competências, a nova base supõe uma revisão da atitude docente. Quanto a isso, a discursividade do papel docente, animada pela implementação da BNCC, esboça o professor como uma espécie de mediador, de tutor, o qual auxiliaria e orientaria o alunado ante o percurso da construção de um trajeto autoral no processo de aprendizagem e aquisição de conhecimentos. No que tange ao ensino de Arte e, mais especificamente, de teatro, no âmbito do ensino fundamental, preconiza a BNCC:

No Ensino Fundamental, o componente curricular Arte está centrado nas seguintes linguagens: as Artes visuais, a Dança, a Música e o Teatro. Essas linguagens articulam saberes referentes a produtos e fenômenos artísticos e envolvem as práticas de criar, ler, produzir, construir, exteriorizar e refletir sobre formas artísticas. A sensibilidade, a intuição, o pensamento, as emoções e as subjetividades se manifestam como formas de expressão no processo de aprendizagem em Arte. O componente curricular contribui, ainda, para a interação crítica dos alunos com a complexidade do mundo, além de favorecer o respeito às diferenças e o diálogo intercultural, pluriétnico e plurilíngue, importantes para o exercício da cidadania. [...] A aprendizagem de Arte precisa alcançar a experiência e a vivência artísticas como prática social, permitindo que os alunos sejam protagonistas e criadores. (BRASIL, 2017, p. 193).

O Teatro instaura a experiência artística multissensorial de encontro com o outro em performance. Nessa experiência, o corpo é lócus de criação ficcional de tempos, espaços e sujeitos distintos de si próprios, por meio do verbal, não verbal e da ação física. Os processos de criação teatral passam por situações de criação coletiva e colaborativa, por intermédio de jogos, improvisações, atuações e encenações, caracterizados pela interação entre atuantes e espectadores. 0 fazer teatral possibilita a intensa troca de experiências entre os alunos e aprimora a percepção estética, a imaginação, a consciência corporal, a intuição, a memória, a reflexão e a emoção. (BRASIL, 2017, p. 194).

No documento em questão, entre as dez competências específicas de Arte indicadas para o ensino fundamental, vale destacar a oitava, intimamente presente na discursividade que alia teatro e educação pela perspectiva da figura de um professor mediador, ao qual caberia: "desenvolver a autonomia, a crítica, a autoria e o trabalho coletivo e colaborativo nas artes" (BRASIL, 2017, p. 198). 
Isso posto, uma breve incursão pela discursividade presente em revistas do campo educacional no que tange, primeiramente, ao ensino do teatro na escola, e, atrelado a isso, à função-professor de teatro, parece indicar que as diferentes instâncias constituintes do campo da pedagogia do teatro logo trataram de se moldar aos paradigmas propostos pela BNCC.

Os discursos que seguem foram auferidos no âmago da pesquisa docente "As potencialidades da noção de Arquivo para investigações no campo da Pedagogia do Teatro", a qual objetivou arquivar artigos que versam sobre a pedagogia do teatro publicados em revistas do campo educacional - indicadas nas referências bibliográficas.

Um rápido apanhado das justificativas para o ensino do teatro na escola, de acordo com tais revistas, revela motivos reiterativos e em pleno diálogo com os ditames da BNCC. Entre eles: "o teatro constituiu um território de 'exercício de si', instrumento para lidar com a vida e com o outro, teatro como possibilidade de novas experiências e outros caminhos" (ZILIANI, 2013, p. 260); "a visão histórica indica que o teatro quase sempre foi concebido como um excelente aliado à educação, por mais distintas que fossem as épocas e mais diversos os objetivos pedagógicos" (GOHN; HANSTED, 2013, p. 214); "acreditamos no teatro em sala de aula enquanto prática educacional potencializadora de uma educação crítica" (DOLCl; REZENDE, 2016, p. 149); "o teatro é, sem dúvida, um dos grandes recursos pedagógicos. Levando a criança a vivenciar outros papéis, ele possibilita, de forma lúdica, que ela trabalhe o seu egocentrismo através do jogo cênico" (RIBEIRO; RODRIGUES, 1995 , p. 22); "o estudo realizado nos fez entender a criação teatral como uma possibilidade de troca e de um novo olhar para o encontro com o outro, no qual os sujeitos aprendem entre si e se enriquecem mutuamente" (COSTA, MUNHOZ, SCHNEIDER, 2016, p. 74); "nesse exercício dialógico e dialético exercitamos: falar e escutar, criticar e propor, refletir e expressar o pensamento, exercícios fundamentais para a reflexão crítica não só dos elementos constituintes do Teatro como também da constituição de nossa sociedade" (Silva, 2006, p. 114); além de:

Nesse contexto, o teatro pode se constituir num "método" de intervenção para a construção do pensamento crítico dos estudantes. Ao mesmo tempo, o teatro possibilita o aprimoramento da nossa capacidade ética e o exercício da razão sensível e, assim, dá lugar à resistência aos racionalismos atualmente vigentes na nossa sociedade. (FREITAS; GONÇALVES, p. 212, 2018).

O teatro é extremamente motivador para crianças e adolescentes; afeta-os nos aspectos emocional, cognitivo, motor e social. Exige também mobilização da atenção, da percepção e da memória, compreensão textual, capacidade de jogar com as palavras; trabalha a expressividade e a imaginação. (OLIVEIRA; STOLTZ, 2010, p. 89).

[...] A arte teatral pensada como ferramenta de crescimento pessoal vai desencadear atitudes autônomas e conscientes nos jovens, levando-os a repensar e avaliar suas escolhas pessoais e culturais e, quem sabe, optar por serem consumidores ou produtores da verdadeira arte, ou seja, da arte que possibilite sua emancipação e seu crescimento. (GRAZIOLI, 2008, p. 14).

Defende-se aqui que a Arte e o teatro, assim melhor dimensionados, podem ser resgatados como instrumentos fundamentais na formação dos cidadãos do amanhã deste país emergente e que sonha ser um exemplo de prosperidade, a qual, espera-se, não seja apenas econômica, mas fundamentalmente humana. (CEBULSKI; LOOS-SANT'ANA; SANT'ANA-LOOS, 2013, p. 69).

O teatro, integrado a uma proposta curricular crítico-emancipatória, na escola, permite para além do trabalho com os conteúdos, experienciar e apreender princípios importantes para a construção de uma sociedade democrática, tais como solidariedade, respeito às diferenças, escuta, diálogo, participação e outros. (KRUPPA; VOLTAS, 2016, p. 327).

Como nota-se, variam os autores, as pesquisas e os objetivos das investigações, mas as justificativas para a prática do teatro em contextos educacionais são reincidentes. 
Já no que tange à função-professor de teatro, pode-se encontrar: a

[...] funcionalidade docente significa exercer o ensino com criatividade e criticidade, aspectos que podem ser considerados ao fazermos uso do teatro como um instrumento de ensino e de aprendizagem. (FREITAS; GONÇALVES, p. 204, 2018).

[...] a função primordial do professor é organizar o meio de modo a provocar o interesse da criança e levá-la a agir para aprender, pois é a atividade do sujeito sobre o mundo que lhe permite apropriar-se do conhecimento e da cultura. (OLIVEIRA; STOLTZ, 2010, p. 80).

[...] o papel do professor é, assim, organizar e intermediar a relação do aluno com o meio social, preparando e orientando as experiências às quais se expõe o aluno. (CEBULSKI; LOOS-SANT'ANA; SANT'ANA-LOOS, 2013, p. 58).

[...] o professor de teatro precisa estar em constante sintonia com as manifestações culturais e artísticas assimiladas ao teatro pelos seus alunos. Só assim conseguirá reunir elementos que o permitam construir intervenções pedagógicas significativas para as crianças, verdadeiras protagonistas do processo de construção do conhecimento teatral. (SANTOS, 2005, p. 240).

[...] sendo assim, cabe ao Pedagogo, profissional responsável pelos processos de ensino-aprendizagem em diferentes contextos, atuar como mediador e facilitador nos processos de formação humana e profissional. (MARTINS, 2009, p. 107).

Como numa espécie de espelhamento, ou se preferir, recíproca apropriação, as diretrizes para o ensino de Arte, e mais especificamente de teatro, presentes na BNCC, como pode-se ver, são naturalmente identificadas e disseminadas pela discursividade de educadores e pesquisadores do campo, autores dos artigos acadêmicos alvo desta reflexão. Como campos discursivos contemporâneos, em ambos ecoa, ao eleger o corpo como epicentro do processo educativo almejado, o ensino do teatro como fundamental à potencialização de uma educação crí- tica; ao exercício da coletividade, da sociabilidade, da solidariedade e da empatia; ao reconhecimento de si e do outro, por meio do desenvolvimento de potencialidades sensíveis, reflexivas, expressivas, criativas, imaginativas; ao exercício da ética atrelado à emancipação e ao crescimento; entre outros.

Para que tais habilidades e competências sejam atingidas, enfatiza-se o professor de teatro como aquele que, imbuído de senso crítico e criativo, se lança ao desafio processual de organizar de forma instigante o meio no qual o aluno aprenderá por meio de sua própria ação interessada. Cabe a esse professor apenas orientar e mediar a relação do aluno, protagonista do processo, com o meio social. Percebe-se implícita a essa postura os ecos de uma pedagogia construtivista (FRANCO, 1998), na qual o professor "deve organizar a interação do estudante com os conteúdos através de problematizações e provocações, para que o próprio estudante construa seu conhecimento a partir dessa mediação" (MOURA; CAREGNATO, 2019, p. 491). Para os mesmos autores, o construtivismo proporia a perspectiva de professor "que mais se aproxima de uma relação ideal de ensino-aprendizagem em Teatro, pelo fato de permitir ao educador uma posição interventiva, mas, principalmente, ao educando um aspecto ativo, pautado na ação-reflexão" (MOURA; CAREGNATO, 2019, p. 495).

Disso, uma questão se faz urgente: tal posição coadjuvante relegada ao professor-mediador, em decorrência de uma suposta garantia do alcance do aclamado par autonomia e liberdade do alunado, no limite, não poderia significar o abandono das novas gerações via desresponsabilizações docentes ante um mundo pregresso?

Debruçada sobre essa indagação, a presente reflexão se valerá de duas produções - ainda que artísticas, exógenas às práticas teatrais - como fonte de inspiração para alçar o voo reflexivo pretendido. Em linhas gerais, interessa lançar luz sobre as posturas esperadas por parte desse professor de teatro ansiado pelas proposições previstas na BNCC, com o fito de indagar sobre os possíveis 
esvaziamentos e desresponsabilizações atinentes às práticas docentes, às quais, como se viu, inspiram a função-professor, de modo geral, como espécie de mero tutor a mediar o trânsito autônomo da construção do conhecimento discente.

\section{Sobre responsabilidade,} tradição e um mundo a ser narrado

A pensadora alemã Hannah Arendt (2009), ao refletir sobre a crise educacional, expõe que a ineficácia americana nesse campo estaria pautada na operação de um paradoxo: ao mesmo tempo em que a América se portaria como o grande laboratório das novas empreitadas educativas, abrindo-se servilmente e indiscriminadamente às teorias modernas da pedagogia, denunciaria em termos práticos, pautados sobretudo por sistemas de avaliação seriados e em massa, a bancarrota da ideia de educação progressista. Para a autora, esse contexto seria resultado da tendência americana em "igualar ou apagar tanto quanto possível as diferenças entre jovens e velhos" (ARENDT, 2009, p. 229). Isso presumiria a existência de "um mundo da criança e uma sociedade formada entre crianças, autônomas e que se deve, na medida do possível, permitir que elas governem" (ARENDT, 2009, p. 230). Os adultos se prestariam, tão somente, ao serviço de auxiliar esse governo.

A autoridade que diz às crianças individualmente o que fazer e o que não fazer repousa no próprio grupo de crianças - e isso, entre outras consequências, gera uma situação em que o adulto se acha impotente ante a crianças individual e em contato com ela. Ele apenas pode dizer-lhe que fala aquilo que lhe agrada e depois evitar que o pior aconteça. (ARENDT, 2009, p. 230).

Emancipada da autoridade adulta, a criança estaria sujeita à autoridade da tirania da maioria de acordo com Arendt, ainda mais terrível e verdadeiramente tirânica. Banidas do mundo dos adultos, estariam as crianças "jogadas a si mesmas, ou entregues à tirania de seu próprio grupo, contra o qual, por sua superioridade numérica, elas não podem se rebelar, contra o qual, por serem crianças, não podem argumentar, e do qual não podem escapar para nenhum outro mundo" (ARENDT, 2009, p. 231).

Assim, tomando a escola como território fundamental de transição da família - campo privado -, para o mundo - campo público -, a autora defende que a criança deve ser introduzida aos poucos no mundo, dada sua condição de ser recém-chegado a esse local com o qual ainda não mantém familiaridade.

$\mathrm{Na}$ esteira desse pensamento, o educador teria de se portar "em relação ao jovem como representante de um mundo pelo qual deve assumir a responsabilidade" (ARENDT, 2009, p. 239). Ao assumir sua responsabilidade por um mundo pregresso ao aluno, ou seja, criado por mãos mortais e que o serve de morada por tempo determinado, o educador, responsável por "ensinar à criança como o mundo é, e não instruí-la na arte de viver" (ARENDT, 2009, p. 246), fundaria sua autoridade, atitude sine qua non para essa relação.

Estabelecendo diferenciações entre autoridade e atitudes autoritárias e totalitárias, Arendt apresenta que "a autoridade foi recusada pelos adultos, e isso somente pode significar uma coisa: que os adultos se recusam a assumir a responsabilidade pelo mundo ao qual trouxeram as crianças" (2009, p. 240).

Com isso a autora abre caminho para estabelecer pontes entre a educação e a tradição ao explicitar que levando em consideração a potência do novo e do revolucionário inerente à criança, "ela [educação] deve preservar essa novidade e introduzi-la como algo novo em um mundo velho, que, por mais revolucionário que possa ser em suas ações, é sempre, do ponto de vista da geração seguinte, obsoleto e rente à destruição" (ARENDT, 2009, p. 243).

Esta reflexão arrisca estabelecer, neste ponto, uma aproximação entre o pensamento de Hannah Arendt e a função do narrador, definida pela perspectiva de seu conterrâneo Walter Benjamin. Tomando a ação de narrar como "a faculdade de intercambiar experiências" (BENJAMIN, 1994, p. 198), Benjamin defende a tese de que a humanidade que resultou do mundo pós Primei- 
ra Guerra Mundial teria perdido paulatinamente a capacidade de narrar experiências comunicáveis. Entrementes, estaria também comprometida a capacidade dos cidadãos de viverem significativas experiências. $\mathrm{O}$ autor expõe que o narrador seria um homem dotado da capacidade de dar conselhos.

Mas, se "dar conselhos" parece hoje algo antiquado, é porque as experiências estão deixando de ser comunicáveis. Em consequência, não podemos dar conselhos nem a nós mesmos nem aos outros. Aconselhar é menos responder a uma pergunta que fazer uma sugestão sobre a continuação de uma história que está sendo narrada. [...] O conselho tecido na substância viva da existência tem um nome: sabedoria. A arte de narrar está definhando porque a sabedoria - o lado épico da verdade - está em extinção. (BENJAMIN, 1994, p. 200-201).

O professor-narrador, portanto, seria aquele que ao narrar o mundo aos seres que nele acabaram de chegar, valendo-se, sobretudo, das experiências comunicáveis, legitimaria sua atitude docente pelo exercício de sua responsabilidade e autoridade.

Reconhece-se que esses textos já foram amplamente disseminados em discussões do campo educacional. Por isso, indica-se que a originalidade da presente reflexão talvez esteja no gesto procedimental de friccionar outras fontes ao pensamento de Arendt e de Benjamin: trata-se de traçar uma abordagem da função-professor de teatro em diálogo com o filme Teorema, do italiano Pier Paolo Pasolini, e a obra literária Fahrenheit 451, do norte-americano Ray Bradbury.

\section{Sobre a distopia de um mundo destituído} da função-professor

Fahrenheit 451, obra de autoria do escritor norte americano Ray Bradbury (1920-2012), nos apresenta uma sociedade distópica, situada em um futuro no qual ler livros implica em crime, cuja pena pode custar a vida do infrator.

Nessa sociedade, de um governo assumidamente ineficiente, despótico e ávido por impostos, os cidadãos, em prol da oferta de uma suposta felicida- de, são saturados de dados insignificantes. Tais habitantes são tomados pela ilusória sensação de serem absolutamente brilhantes quanto à prerrogativa de estarem bem informados. Nesse contexto, filosofia ou sociologia, supostamente dadas como terrenos movediços, capazes de tornar a todos infelizes com teorias e pensamentos contraditórios, devem ser execradas.

Soma-se ao já exposto a existência de casas antichama, fato que delega nova função aos bombeiros. Braço forte do controle de uma polícia vigiante e onisciente, eles se tornam os responsáveis pela investigação e posterior queima domiciliar de livros ainda existentes. Operam pelo oposto, não mais combatem casas em chamas como no passado.

O protagonista da narrativa é um membro da corporação: Guy Montag. Certo dia Montag cruza com sua vizinha Clarisse. A jovem garota de 17 anos que se autorrotula como anormal por não ter amigos, instiga o bombeiro a olhar para o mundo de outras formas, focando nos detalhes irrelevantes da natureza, assim como no lado obscuro da infelicidade e futilidade das pessoas ao seu redor. Sempre pronta a lançar perguntas impensáveis, duas delas desnorteiam Montag: "você nunca lê nenhum livro que queima?"; "você é feliz?".

Passado um tempo, o empenhado bombeiro se dá conta de que fazia longa data que não encontrava a jovem vizinha. Montag fica sabendo, então, que ela e sua família haviam sido eliminadas pelo Estado por conta de suas felicidades e questionamentos incomuns. Intrigado e comovido com a morte de Clarisse, Montag, ainda sob o efeito irreversível de um olhar deslocado, é tomado por melancolia, passando a questionar a função dos livros. Não se contém e, a cada casa invadida para incineração, leva de recordação uma obra literária. Só poderia ter a resposta procurada caso se embrenhasse pela leitura dos objetos confiscados.

Em dado momento de sua labuta, Montag se vê diante de mais uma situação que se somará ao deslocamento anterior. Invade com sua equipe a residência de uma mulher que mantinha a posse de um arsenal de livros. Ainda que correndo o risco de 
ser queimada junto à montanha de papel, a mulher não se demoveu. Imersa entre livros e querosene, antes que a ameaça dos bombeiros se efetivasse, por conta própria riscou o fósforo de seu próprio fim. Impactado pela convicção da mulher, Montag rumina haver algo de muito importante nos livros.

O chefe da corporação descobre a grave infração de Montag e tenta convencê-lo sobre a inutilidade da literatura. Preocupado, Montag se alia ao Sr. Faber, um velho professor - função ultrapassada, colocada para escanteio, assim como escritores, historiadores, linguistas -, tendo em vista, primeiramente, descobrir a utilidade dos livros, e, por fim, se vingar dos bombeiros.

Um dia Montag adentra sua casa e encontra as amigas de sua esposa. Não se contém e para elas lê alguns poemas. É denunciado pela própria esposa. Sua casa é incendiada por seus colegas de trabalho. Ao longo disso queima vivo seu chefe Beatty. Não há outra opção a não ser fugir.

Orientado e ajudado pelo Sr. Faber, Montag parte em direção à periferia da cidade. Lá encontra uma espécie de comunidade formada por ex-catedráticos e escritores, os quais ocupam seus dias lendo livros para que, depois de armazenados na memória, as obras sejam queimadas. Esses anônimos intelectuais assumem a função de manter intacto e seguro o conhecimento que pensam ser relevante. A estratégia era passar os livros para os filhos, de boca a boca, para que esses servissem no futuro a outras pessoas. Cada homem elegia um livro que desejava se lembrar. Homens-livros a vagarem pela floresta recitando reiteradamente trechos dos livros escolhidos com o fito de preservar uma herança por eles tida como fundamental.

A narrativa termina fazendo menção à Fênix, pássaro da mitologia grega que a cada cem anos construía uma pira e se consumava em suas chamas, ressurgindo, renovada, das cinzas. A humanidade, segundo a reflexão das marginais personagens dessa sociedade distópica, faria o mesmo, entretanto, com a vantagem de poder ser consciente da estupidez dos atos cometidos.

\section{Sobre encontros efêmeros e deslocamentos irreversíveis}

Teorema, obra fílmica de autoria do italiano Pier Paolo Pasolini (1922-1975), exibe nas primeiras sequências de cenas, em tom sépia e sem que se ouça o que dizem suas personagens, uma família burguesa, que habita os arredores de Milão, em seu cotidiano: o pai em sua fábrica; os filhos, um casal de adolescentes, saindo do colégio entre colegas e paqueras; a mãe lendo em seu leito; a empregada na organização dos afazeres do lar.

No jantar, um telegrama é aberto pelo chefe da família: "chego amanhã". As cenas que seguem agora dão voz e cores às personagens e suas ações. Em uma festa, apresenta-se a personagem que acabou de chegar, mas sem que se diga de fato quem possa ser. Figura simpática, ainda que sensível, carrega traços de uma masculinidade em evidência. É afeita a leituras densas, entre elas Rimbaud.

Sem que se saiba ao certo o que se passa, a sequência seguinte anuncia que as personagens de antes não serão mais as mesmas depois desse encontro. A começar pela empregada, que em um misto de culpa cristã e desejo, após observar o estrangeiro no jardim, ensaia se matar asfixiando-se com gás de cozinha. É salva pelos braços do prestativo rapaz.

A sequência das próximas cenas, protagonizadas pelo estrangeiro em privacidade com cada um dos membros da família, revela o que essa figura desperta nas demais. Sem exceção, todos são animados em seus desejos e pulsões libidinais, forças que de chofre se chocam aos ideais morais que parecem carregar.

É chegado o dia em que a família recebe um novo telegrama: a mensagem informa que o forasteiro deve partir já no dia seguinte.

Consternados ante à notícia, segue-se, novamente, uma sequência de cenas nas quais os membros da família, a sós com o estrangeiro, relatam o que se passou nesse encontro. Filho: "Não me reconheço mais. O que me tornava igual aos outros foi destruído. Eu era como os outros, talvez, com muitos defeitos... Os meus e os do meu mundo. Você me tirou da ordem natural das coisas". Mãe: "Agora per- 
cebo que nunca tive interesse real por nada. Não falo de grandes interesses, mas, dos pequenos, como o do meu marido pela fábrica, do meu filho pelos estudos, de Odetta pela família. Eu? Nada. Não entendo como consegui viver nesse vazio. E vivi. Se alguma coisa, um pouco de amor instintivo pela vida, era estéril, como um jardim onde ninguém passa. Na verdade, esse vazio continha valores falsos e mesquinhos, de um acúmulo horrível de ideias erradas. Agora eu percebo. Você deu à minha vida um interesse total e real". Filha: "Nosso encontro fez de mim uma garota normal. Finalmente encontrei uma solução para a minha vida. Antes, eu não conhecia os homens. Tinha medo deles. Só amava meu pai. Mas agora, partindo, não só me atira para frente, mas me faz seguir adiante. Era isso que queria? Agora a dor de perder você provocará em mim uma nova queda mais perigosa que o mal que havia dentro de mim antes da minha breve cura devido à sua presença. Eu nunca havia conhecido esse mal, mas agora sim. Através do bem que você me fez, me conscientizei do meu mal". Pai: "Você veio aqui para destruir. Em mim, a destruição que causou é total. Destruiu a ideia que sempre fiz de mim. Não consigo ver nada que possa reintegrar-me à minha identidade. O que você propõe? Um escândalo equivalente a uma morte civil, minha destruição total. Como pode fazer isso um homem acostumado à ideia da ordem, do amanhã e, sobretudo, da posse?". A empregada nada diz ao entregar as malas ao estrangeiro. Somente beija-lhe as mãos.

Com a despedida, a família se fragmenta.

A empregada parte para um vilarejo, no qual, após viver em voto de silêncio, passando seus dias sentada no banco de um pátio externo, atrai multidões de devotos, transformando-se em uma espécie de santa a curar os males da vizinhança. Certo dia, ascende acima do telhado das casas, mantendo-se suspensa em posição de cruz. Após, volta ao solo e pede para ser enterrada viva.

A filha entra em estado de surto ao rever as fotos do hóspede. Catatônica, é transferida para uma clínica psiquiátrica.
O filho parte de casa e dá vazão aos seus dotes como artista plástico, passando seus dias a pintar obras de fortes traços expressivos, utilizando diferentes técnicas, suportes e materiais.

A mãe segue estrada afora, dando carona e mantendo relações sexuais com todos os homens que cruzam o seu caminho. O pai, a caminho da fábrica, tem a ideia de dela se desfazer, entregando-a aos seus operários. Na estação de trem de Milão, ao avistar desejosamente outro homem, mais jovem do que ele, despe-se em público. Caminha sem rumo, terminando nu sobre as dunas escuras de um terreno arenoso e desértico nas cercanias de um vulcão.

\section{Sobre a imprevisibilidade de um encontro em contexto sabido, mas entre sujeitos desconhecidos}

Como pode-se ver, as obras citadas apresentam em comum o fato de que suas personagens, pelo encontro com um outro, passam a questionar os modos pelos quais são governadas. Aqui, entende-se por governo a atividade interessada em produzir sujeitos, moldá-los, afetá-los em suas condutas para que possam ser sujeitos específicos (FOUCAULT, 2004). A atitude crítica que toma conta dessas personagens, paulatinamente se traduz em impulso para que desejem coisas outras. Montag, personagem de Ray Bradbury, é inspirado por certa ideia de vivacidade ao cruzar com sua vizinha Clarisse, e impassividade, ao cruzar com a mulher que se recusa a largar seus livros, mesmo que isso the custe a vida. Já a família delineada por Pasolini, ao receber o estrangeiro, é tirada da ordem natural das coisas.

Pasolini apresenta uma personagem que traduz em atitude as narrativas endereçadas a questionar os modos de se governar a existência. Já Ray Bradbury nos lega, por meio de seus ex-professores a vagarem pelo mundo utilizando como estratégia a narração de obras literárias entre gerações, uma forma de lidar com a tradição, uma linha narrativa entre vivos e mortos, ao sabor do legado de Arendt e Benjamin, maneira não menos questionadora, portanto, dos modos costumeiros de governo da existência. 
Longe de uma leitura psicanalítica, ou seja, descartando certo teor messiânico, salvacionista, pessimista e de dependência que possa soar dessas personagens e de suas relações, o que interessa a esta reflexão é pensar sobre a potência de deslocamentos inerentes ao encontro imprevisível, efêmero e irreversível entre vidas desconhecidas desejosas de velhas e novas narrativas sobre o mundo. Tal qual a imprevisibilidade do compromisso inevitável entre o professor e o aluno, ao mesmo tempo objetos e sujeitos de um encontro no qual se sabe, mesmo que artificialmente, sobre qual pretexto acontecerá, sem que se saiba efetivamente entre quem ele se dará - geralmente professores não escolhem seus alunos, assim como a recíproca também tende a ser verdadeira.

Ensaia-se, assim, uma perspectiva para a função-professor de teatro que se opõe a uma prática docente isenta e acrítica, na qual, a figura adulta, destituída de sua autoridade, ao contrário de se responsabilizar pelo mundo, portar-se como mera mediadora entre esse mundo e seus alunos, a serviço de uma suposta autonomia e liberdade de escolha garantidas aos últimos.

É comum referir-se às práticas da pedagogia teatral como campo privilegiado para a produtividade de modos de subjetivação, os quais, na esteira do legado de Foucault, se referem a: "eu chamaria de subjetivação o processo pelo qual se obtém a constituição de um sujeito, mais precisamente de uma subjetividade, que evidentemente não passa de uma das possibilidades dadas de organização de uma consciência de si" (FOUCAULT, 2010, p. 262). Trata-se da prática teatral como lócus na qual ao mesmo tempo em que o sujeito se constitui, torna-se objeto reconhecível e analisável de relações de conhecimento e poder, ou seja, de relações de veridicção, "entendidas como as formas pelas quais se articulam, sobre um campo de coisas, discursos capazes de serem ditos verdadeiros ou falsos" (FOUCAULT, 2010, p. 235).

Isso posto, o que se ensaia aqui é um professor de teatro interessado em enfatizar o outro lado dessa mesma moeda. Ele não focaria seus esforços na face da constituição de subjetividades, mas sim, inspirado pelas personagens de Pasolini e de Bradbury, almejaria instaurar processos de desformação de práticas, de desassujeitamentos, de destituição dos regimes de veridicção. Frente a frente com narrativas ávidas por serem conhecidas para que possam ser, a partir do corpo em jogo e da expressão, reinventadas - aqui atribui-se tais funções como especificidades das práticas teatrais -, aos sujeitos da pedagogia do teatro seria dada a possibilidade de se deslocarem continuamente, constituindo-se como sujeitos temporários de territórios imprevistos.

Foucault, nesse caso influenciado por Kant, expõe que o processo de desassujeitamento opera no âmago daquilo que chamou de atitude crítica: o questionamento da ordem de "como não ser governado assim, por isso, em nome desses princípios, em vista de tais objetivos e por meio de tais procedimentos, não dessa forma, não para isso, não por eles" (FOUCAULT, 1990, p. 38). Ainda nessa linha de pensamento, a presente reflexão investe na ideia de que essa atitude crítica como gatilho para o processo "de desassujeitamento em relação ao jogo do poder e da verdade" (FOUCAULT, 1990 , p. 42), pressupõe que, conforme nos inspira a aproximação entre Benjamin e Arendt, o mundo tenha sido anteriormente narrado e apresentado, de forma responsável, aos sujeitos da educação.

Nota-se que o professor de teatro aqui ensaiado, mesmo que busque outros entendimentos do espaço das práticas teatrais, não encontra na ladainha das competências gerais ofertadas pela BNCC um impedimento. Versa essa ladainha sobre valorizar e utilizar conhecimentos historicamente construídos, exercitar a curiosidade, a investigação, a reflexão, a imaginação, a criatividade, valorizar a diversidade de saberes e práticas, fomentar o pensamento crítico e a argumentação, e assim por diante. Tudo isso pode contemplar os horizontes dessa espécie de professor de teatro a narrar o mundo pregresso. Portanto, trata-se de assumir outras posturas, logo, mudanças metodológicas e procedimentais, mais do que temáticas.

Recorrendo novamente ao final da obra de Bradbury, a saber, a menção ao mito da Fênix, porven- 
tura o professor de teatro, ao narrar o mundo pregresso, possa alumiar a consciência dos sujeitos da educação no que tange aos processos de estupidez já cometidos - atitude aqui próxima ao que Foucault nomeou como atitude crítica. A consciência e a crítica são especificidades do humano, sua salvaguarda para que, quem sabe, um dia as piras funerárias deixem de ser inflamadas e, consequentemente, a humanidade não mais careça de nelas se lançar. A possibilidade dessa emancipação vale-se da tomada de consciência, que aqui é sinônimo de responsabilidade e de crítica, ainda que tal processo não seja a garantia unânime para o fim da estupidez. Ou seja, ainda que grande parte de seus franqueados, inclusive no campo da pedagogia do teatro, publicizem o contrário, o gesto docente traduz-se como um investimento às cegas, destituído de garantia alguma. Quiçá essa seja a lídima graça dessa função.

\section{Referências}

ARENDT, Hannah. A crise da educação. In.: ARENDT, Hannah. Entre o passado e o futuro, p. 221-247. São Paulo: Perspectiva, 2009.

BENJAMIN, Walter. O narrador: considerações sobre a obra de Nikolai Leskov. In.: BENJAMIN, Walter. Magia e técnica, arte e política: ensaios sobre literatura e história da cultura, p. 197-221. São Paulo: Brasiliense, 1994.

BRASIL. Base Nacional Comum Curricular (BNCC). Educação é a Base. Brasília, MEC/CONSED/UNDIME, 2017.

BRADBURY, Ray. Fahrenheit 451. São Paulo: Editora Globo, 2012.

CEBULSKI, Márcia Cristina; LOOS-SANT'ANA, Helga; SANT'ANA-LOOS, René Simonato. A arte, a afetividade e o sistema educacional: o desenvolvimento humano em questão. Cadernos de Pesquisa: Pensamento Educacional, Curitiba, v. 8, n. 20, p. 55-72, set./dez. 2013.
COSTA, Cristiano B. da; MUNHOZ, Angélica V.; SCHNEIDER, Cristiane. Do jogo teatral ao teatro como criação. Imagens da Educação, v. 6, n. 2, p. 67-74, 2016.

DOLCI, Luciana Netto Dolci; REZENDE, Pauline Apolinário Czarneski. O teatro na sala de aula: potencialidades do sentido estético no cotidiano escolar. Educação em Foco, ano 19, n. 29, p. 13-34, set/ dez. 2016,

FOUCAULT, Michel. Ditos e escritos V: ética, sexualidade e política. Rio de Janeiro: Forense Universitária, 2010.

FOUCAULT, Michel. Qu'est-ce que la critique? Bulletin de la Société Française de Philosophie, Paris, v. 84, n. 2, p. 35-63, 1990.

FOUCAULT, Michel. Tecnologias de si. Verve, São Paulo, n. 6, p. 321-60, 2004.

FRANCO, Sérgio Roberto Kieling. O Construtivismo e a Educação. Porto Alegre: Mediação, 1998.

FREITAS, Nívia Magalhães da Silva; GONÇALVES, Terezinha Valim Oliver. Práticas teatrais e o ensino de Ciências: o teatro jornal na abordagem da temática do lixo. Educar em Revista, Curitiba, Brasil, v. 34, n. 68, p. 199-216, mar./abr. 2018.

GOHN, Maria da Glória; HANSTED, Talitha Cardoso. Teatro e Educação: um relação historicamente construída. EccoS - Rev. Cient., São Paulo, n. 30, p. 199-220, jan./abr. 2013.

GRAZIOLI, Fabiano Tadeu. Os princípios gerais do teatro na escola e o afastamento da atividade teatral significativa da escola brasileira. Roteiro, Joaçaba, v. 33, n. 1, p. 7-24, jan./jun. 2008. 
KRUPPA, Sonia M. Portella; VOLTAS, Fernanda Quatorze. O teatro na formação dos educandos: as percepções dos educadores de um centro educacional unificado (CEU) da cidade de São Paulo. Revista e-Curriculum, São Paulo, v.14, n.01, p. 307-331 jan./ mar., 2016.

MARTINS, Tatiane Souza. Cooperação: condutor fundamental para a construção de novos saberes. Revista de educação, ciência e cultura, v. 14, n. 1, p. 105-113, jan./jun., 2009.

MOURA, Fábio da Silva; CAREGNATO, Caroline. Um diálogo entre epistemologia, educação e pedagogia teatral. Um diálogo entre epistemologia, educação e pedagogia teatral. Ouvirouver, Uberlândia, v. 15, n. 2, p. 482-496, jul./dez., 2019.

OLIVEIRA, Maria Eunice de; STOLTZ, Tania. Teatro na escola: considerações a partir de Vygotsky. Educar, Curitiba, n. 36, p. 77-93, 2010.

RIBEIRO, Maria Augusta H. W.; RODRIGUES, Maria Lídia Meyer. A literatura em cena: um espaço pedagógico. EDUCAÇÃO: Teoria e Prática, Rio Claro, V. 03, N. 04, p. 22-24, jan./jun., 1995.

SANTOS, Vera Lúcia Bertoni dos. Experiência urbana e conhecimento teatral: romper limites e ampliar espaços. Educação \& Realidade, Porto Alegre, v. 30, n. 2, p. 230-242, jul./dez., 2005.

SILVA, Rilar Lopes da. O teatro-educação enquanto componente curricular no meio rural: uma experência na Escola Comunitária Brilho de Cristal. Revista da FAEEBA - Educação e Contemporaneidade, Salvador, v. 15, n. 25, p. 99-115, jan./jun., 2006.

TEOREMA. Direção de Pier Paolo Pasolini. Itália, 1968, 1 DVD (98min).
ZILLIANI, Rosemeire de Lourdes Monteiro. Invenção da identidade Sul-Mato-Grossense no teatro de uma escola técnica. Acta Scientiarum Education, Maringá, v. 35, n. 2, p. 255-262, jan./jun., 2013.

Recebido: 07/01/2021

Aceito: $27 / 04 / 2021$

Aprovado para publicação: 27/05/2021

Este é um artigo de acesso aberto distribuído sob os termos de uma Licença Creative Commons Atribuição 4.0 Internacional. Disponível em: http://creativecommons.org/licenses/by/4.0.

This is an open-access article distributed under the terms of the Creative Commons Attribution License 4.0 International. Available at: http://creativecommons.org/licenses/by/4.0.

Ce texte en libre accès est placé sous licence Creative Commons Attribution 4.0 International. Disponible sur: http://creativecommons.org/licenses/by/4.0. 